\title{
Study on dermatoses and their prevalence in groups of con- firmed alcoholic individuals in comparison to a non-alcoholic group of individuals
}

\author{
Estudo das dermatoses e sua prevalencia em individuos comprovadamente \\ alcoolistas comparativamente a um grupo de individuos não alcoolistas
}

Maria Cecilia Teixeira de Carvalho Bruno ${ }^{1}$

Maria Aparecida Constantino Vilela²

Carlos Alberto B. Mendes de Oliveira ${ }^{3}$

DOI: http://dx.doi.org/10.1590/abd1806-4841.20131829

\begin{abstract}
BACKGROUND: The direct relationship between alcoholism and dermatoses has been evaluated in recent researches. However, there are few objective surveys that demonstrate and prove a direct relationship between alcohol and a specific dermatosis. ОвјестіvEs: to verify the prevalence of dermatoses in alcoholics, analize the dermatological changes found in these patients and their evolution during alcoholic abstinence. Also, to compare the results obtained with a non-alcoholic control group and with the data found in medical literature. Methods: the dermatologic conditions of 278 alcoholic patients ( 250 men, 28 women) were studied over a period of 4 years, and compared to those of a control group of 271 non-alcoholic individuals ( 249 men, 22 women), members of the Military Police Force. The individuals in both groups were between 20 and 60 years old. RESUlTs: Pellagra, nummular eczema, purpura pigmentosa chronica (also known as pigmented purpuric dermatosis) and psoriasis were more frequent in the group of alcoholics and, apparently, occurred in parallel with alcoholism that seems to play a role in the evolution of these dermatoses. The dermatopathies were more frequent before the age of forty, regardless of factors such as profession, race or gender. CONCLUSION: the association of dermatoses and alcoholism was extremely significant according to the statistical data. Alcoholism can be considered a risk factor for pellagra, psoriasis, nummular eczema and purpura pigmentosa chronica dermatoses, which can, as well, be considered alcoholism indicators.
\end{abstract}

Keywords: Administration, cutaneous; Alcoholism; Skin manifestations; Substance withdrawal syndrome

Resumo FundAmENTOS: A relação direta entre o alcoolismo e as dermatoses vem sendo avaliada em recentes pesquisas. No entanto são poucos os estudos objetivos que demonstram e comprovam uma relação direta entre o álcool e uma determinada dermatose. OBJETIVOs: Verificar a prevalência de dermatoses em alcoolistas, avaliar as alterações dermatológicas encontradas nesses doentes e sua evolução frente à abstinência alcoólica. Comparar os resultados obtidos com um grupo controle não alcoolista e com os resultados encontrados na literatura mundial. MÉTODO: Foram estudados, durante 4 anos, sob o ponto de vista dermatológico, 278 doentes alcoolistas (250 homens, 28 mulheres) comparativamente a 271 indivíduos (249 homens, 22 mulheres) não alcoolistas integrantes da Policia Militar, que constituíram o grupo controle, ambos com idades entre 20 e 60 anos. Resultados: As dermatoses pelagra, eczema numular, púrpura pigmentosa crônica e psoríase foram mais frequentes no grupo dos alcoolistas e aparentemente surgiram paralelamente ao alcoolismo, que parece interferir na evolução destas dermatoses. As dermatopatias foram mais frequentes antes dos quarenta anos, não sendo significativos os fatores profissão, cor e sexo. CONCLUSÃo: a associação das dermatoses com alcoolismo foi altamente significativa, como indicaram os dados estatísticos. O alcoolismo pode ser considerado fator de risco para as dermatoses pelagra, psoríase, eczema numular e púrpura pigmentar crônica, podendo estas serem consideradas indicadoras de alcoolismo

Palavras-chave: Administração cutânea; Alcoolismo; Manifestações cutâneas; Síndrome de Abstinência a Substâncias

\section{Received on 23.04.12.}

Approved by the Advisory Board and accepted for publication on 14.08.2012.

* Work performed at the Hospital Espírita de Marília - Marília (SP), Brazil.

Financial support: none.

Conflict of interests: none.

Dermatologist, MD, MSc at University of São Paulo Medical School (FMUSP) - Professor Of Clinical Mycology at the Pharmacy School at the Federal University of Mato Grosso (UFMT) - Mato Grosso (MT), Brazil.

Assistant MD at the Dermatology Department at the University of São Paulo Medical School Hospital (HC-FMUSP) - São Paulo (SP), Brazil.

Resident of the Dermatology Department at the Santa Casa de Misericórdia de Curitiba- Curitiba (PR), Brazil. 


\section{INTRODUCTION}

Alcohol-related disorders are considered to be of great importance by the public health system, not only due to the effect they have on the individual's somatic and mental state, but also due to the huge impact the problem poses socially. Alcoholism is prevalent in men, at a ratio of three or four men to one woman. ${ }^{1}$

The variation of the incidence of alcoholism in relation to the skin tone depends on the ethnic composition of a particular population. In this research carried out at the Hospital Espírita de Marilia, Marilia, SP, most of the alcoholic patients are white, because the ethnic distribution of the population of Marilia has a higher proportion of white residents than African Americans, Asian and dark-skinned individuals in general. ${ }^{2}$

There are countless surveys that list the harmful effects that the excessive consumption of alcohol causes in all organs. On the other hand, the literature on the association of alcoholism with dermatosis is scarce. It is easy to understand this, especially when we compare the extent and severity of the damage caused by excessive alcohol consumption to the internal organs, with the cutaneous manifestations found in alcoholic patients.

Recent reports have shown that, only a substantial dermatological anamnesis regarding the consumption of alcohol and the familiarization with the cutaneous manifestations found in patients that abuse alcohol would facilitate the identification of skin changes secondary to alcoholism and account for the aggravation and resistance of some dermatosis to the treatments performed. ${ }^{3}$

The cutaneous signs that denote alcohol consumption abuse are widely known. They include jaundice, facial flushing, spider telangiectasia (spider nevus), 'paper money' skin, palmar erythema and ungueal or nail changes (leukonychia). We know that these signs occur when the alcohol consumption has already caused serious hepatic damage, but are not specific of alcoholism, as they may appear in other non-alcoholic patients. ${ }^{4,5}$

The connection between alcoholism and infections is also well known. Alcohol can act directly on the immune system, reducing the cellular and humoral immunity, causing neutrophil dysfunction and leucopenia, thus changing the patient's immune response. Related to this connection, we observe an increase in fungal infections on alcoholics, including onychomycosis and tinea versicolor.,

Recent reports show that other dermatopathies may be an early signal of cases of excessive alcohol consumption, and are considered by some authors as new indicators of alcoholism, especially nummular eczema, chronic purpura pigmented, psoriasis and pellagra.

Nummular eczema is an eczematous condition of unknown etiology that is probably connected to more than one trigger factor. It may occur due to dry skin and to a coagulase-positive staphylococcus bacterial infection. It is believed to be associated with periods of high alcohol ingestion. ${ }^{7}$

Chronic purpura pigmentosa is a condition of unknown etiology, characterized by a chronic inflammatory process of the vascular wall. Some authors have reported occurrence rates of $40 \%$ in alcoholics about 60 years old.

There are quite a number of relevant studies about the connection of psoriasis and alcoholism, although the mechanism has not been fully understood yet. The genetic characteristic is indisputable, with a $30 \%$ occurrence in individuals of the same family, although it does not appear to be influenced by gender but by the relation between cause and effect. Researches show a considerable improvement of the psoriatic lesions when alcoholic abstinence occurs. ${ }^{3,45,8,9}$

Pellagra, a metabolic disease that occurs in malnourished individuals, is always connected to alcoholism, although this fact is not mentioned by some of the authors. The occurrence of classic triad dermatitisdiarrhea-dementia is described in a small number of cases, while cutaneous symptoms and clinical occurrences are more frequent. Digestive and neurological disorders occur most frequently after the dermatosis. Data regarding the occurrence of pellagra in alcoholic patients is debatable both in the national and international literature. ${ }^{10-15}$

The literature also shows that dermatosis, such as seborrheic dermatitis, rosacea and acne vulgaris are also exacerbated by alcohol abuse. ${ }^{4}$

Taking into account that cutaneous disorders associated to alcoholism may be recognized early, with a thorough dermatological exam and a careful investigation of the amount of alcohol consumption, the objective of this study was to verify the prevalence of dermatosis in alcoholic patients. Also, to study the dermatological changes found in these patients and their evolution in face of alcohol abstinence, comparing the results with a non-alcoholic control group and with the results found in the worldwide literature.

This study was also directed to the field of prevention, with the objective to detect earlier, through diagnosis of the cutaneous lesions, signs of alcohol abuse before severe damage to the internal organs occurs. 


\section{CASUISTIC AND METHOD}

This is a cross-sectional study of 278 alcoholic patients (250 men: 188 white, 40 brown, 22 black; 28 women: 14 white, 12 brown, 2 black), whose ages varied between 20 and 60 years old studied from the dermatological point of view after being admitted for alcohol detoxification for an average length of stay of 40 days.

All patients were confirmed alcoholics or drank an average of more than $100 \mathrm{~g}$ of alcohol every day. They manifested behavioral changes and had physical, social, and psychological impairments, as well as strained familial relationships due to the disease.

Patients with genodermatoses, viruses, and those presenting with skin changes related to spider telangiectasia hepatopathies, palmar erythema and leukonychia among others were excluded from the study group.

The control group consisted of 271 military police officers, members of Interior Police Command Four (CPA I- 4) from the city of Marilia -SP on active duty (249 men: 230 white, 40 brown, 4 black and 2 Asian; 22 women: 21 white, 1 brown) aged between 20 and 50 . None of the individuals presented dermatosis, nor had a family history of alcoholism. None of them were chronic or heavy alcohol users, since this would lead to immediate dismissal from the Military Police Force.

The dermatological evaluation occurred weekly. The diagnoses of dermatosis were clinical and all cases had characteristic lesions. When necessary, a direct mycological examination and a Wood lamp exam were performed. The Hospital Espírita de Marilia Ethics Committee did not allow biopsies or photographic documentation of the dermatological cases. For this reason, only the clinically proven cases were included in this report. The dermatoses were not treated, except for those infected with scabies.

Data was submitted to a statistical analysis with the following tests:

Chi-square test of independence, with 1 degree of freedom and relative estimated risk, with the respective confidence interval 95\% (ic 95\%)

Bilateral test for proportion comparison, with normal approximation.

Test for a proportion, with normal approximation, comparing it to 0.50 to conclude if it is a matter of majority, minority or no statistical importance.

\section{RESULTS}

\section{Alcoholic group characteristics}

Regarding gender and race, there was a predominance of male, white individuals, followed by brown and black individuals. The age varied between 20 and 60 , with an average of 42.7 years. (Graphs 1 and 2)

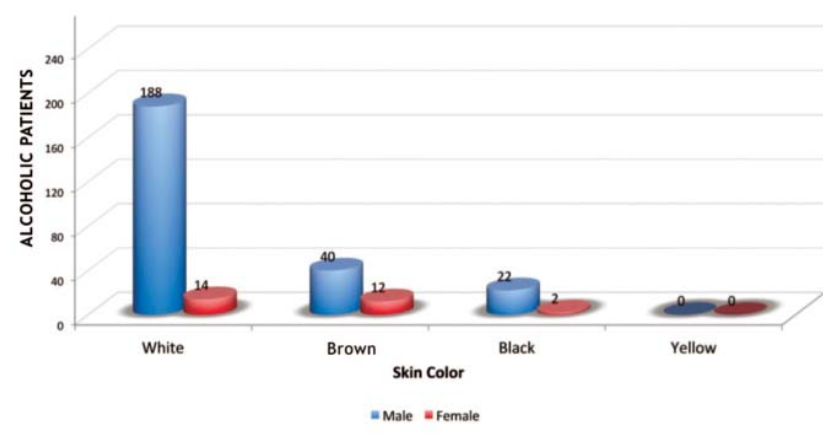

GRAPH 1: Distribution according to skin color and gender of 278 alcohholics

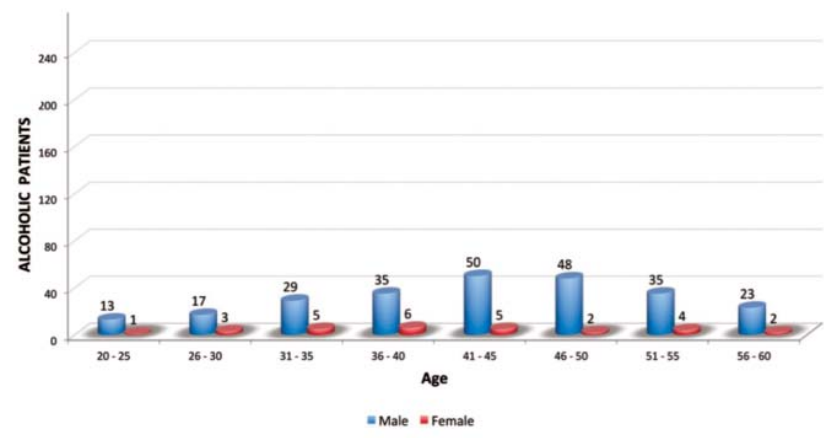

GRAPH 2: Distribution according to age of 278 alcoholics of both genders

The predominant professional activity of male individuals was construction workers, followed by: farm worker, night watchman, machine operator, general services department employee, street vendor, mailman, tailor and lawyers. Professional activities of female individuals in decreasing order of frequency were: no defined profession, followed by cleaning services, laundress, housekeeper, farm worker (Graphs 3 and 4). Dermatoses were found in 114/278 alcoholic male and female. The diagnosis were by order of frequency: athlete's foot, seborrheic dermatitis, pellagra, nummular eczema,, acne vulgaris or cys-

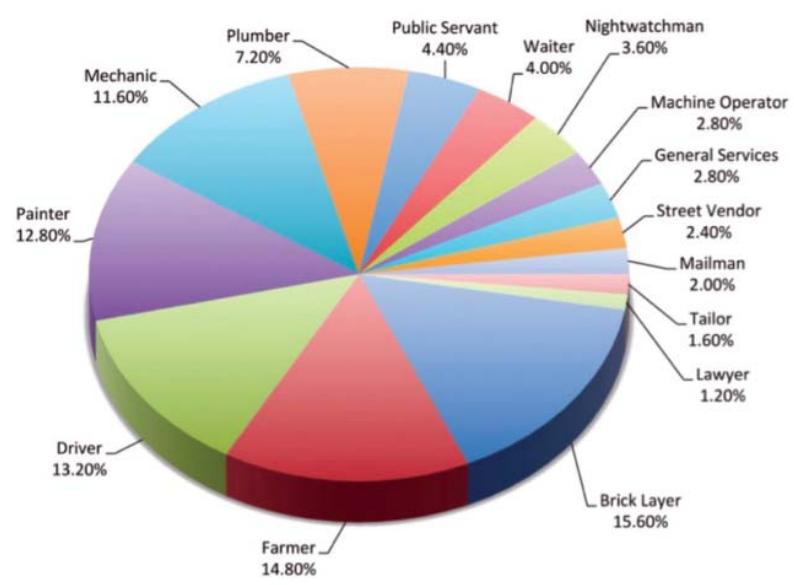

GRAPH 3: Distribution according to activity of 250/ 278 male alcoholics 


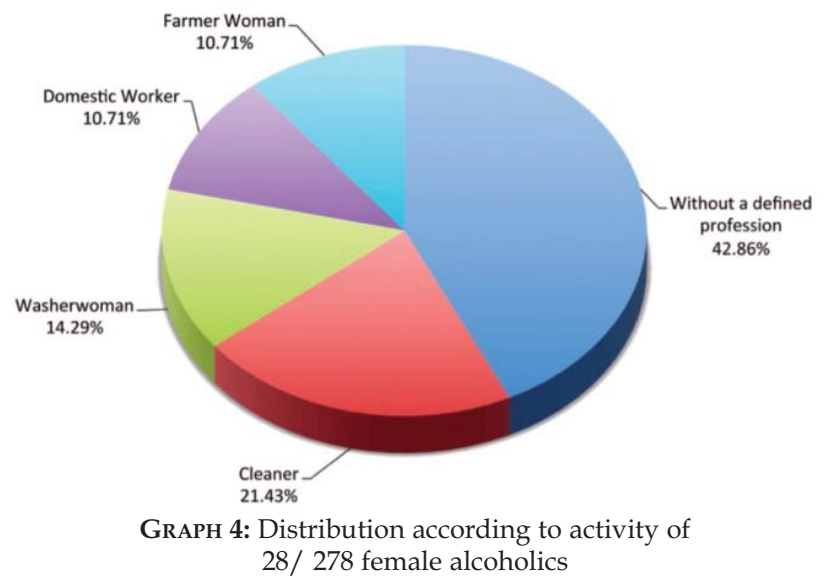

tic acne, psoriasis, pigmented purpuric dermatosis, onychomycosis, contact dermatitis, scabies, xeroder$\mathrm{ma}$, rosacea, tinea versicolor, (or pityriasis versicolor), dyshidrosis, tinea cruris, atopic dermatitis (Graph 5).

\section{Control group characteristics}

Control group individuals were predominantly male, white-skinned followed by black and Asian individuals. Their ages varied from 20 to 50 years with the average of 32.8 years (Graph 6 and 7).

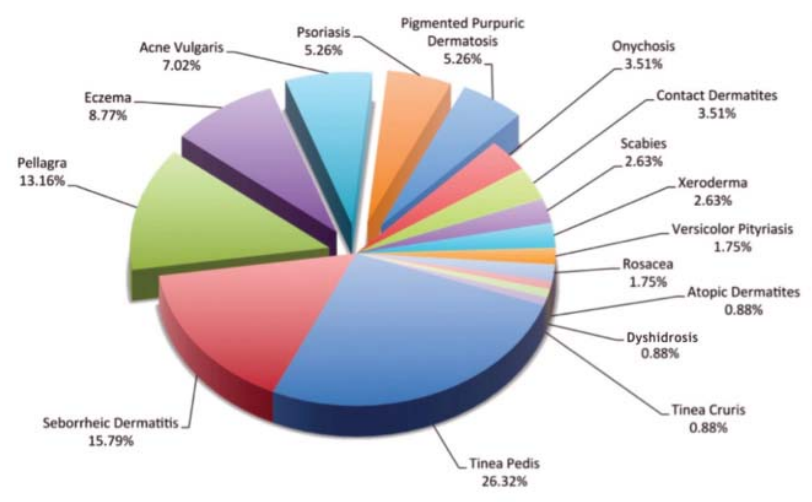

GrAPH 5: Dermatosis found in 114/ 278 alcoholics of booth genders

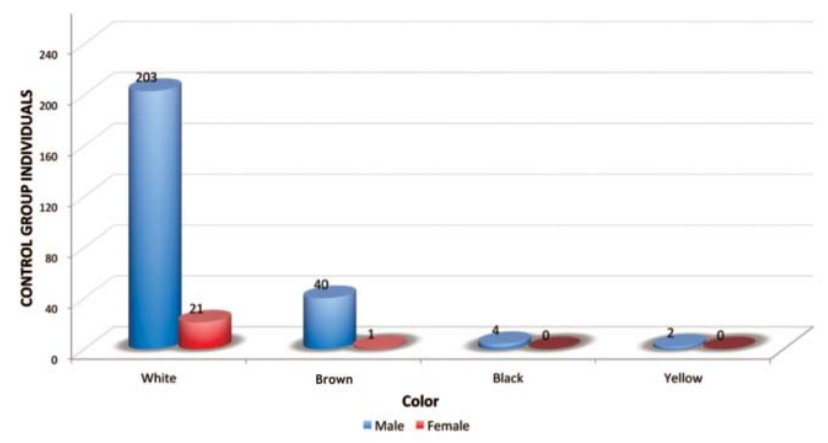

GRAPH 6: Distribution according to skin color and gender of 271 individuals on the control group

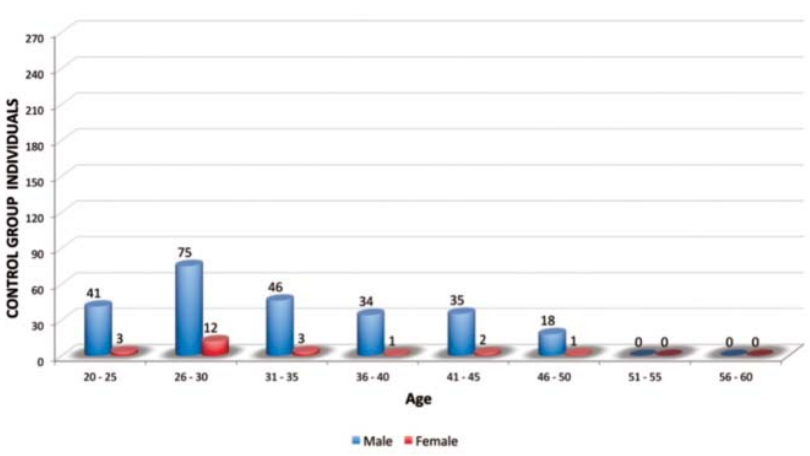

GRAPH 7: Distribution according to age of 271 individuals of both genders on the control group

The dermatoses found in 70 of the 271 individuals, male and female of the control group were by order of frequency: tinea pedis, seborrheic dermatitis, onychomycosis, acne vulgaris, contact dermatitis, pityriasis versicolor, dyshidrosis, tinea cruris, folliculitis, xeroderma, scabies, chronic pigmented purpura, atopic dermatitis (Graph 8).

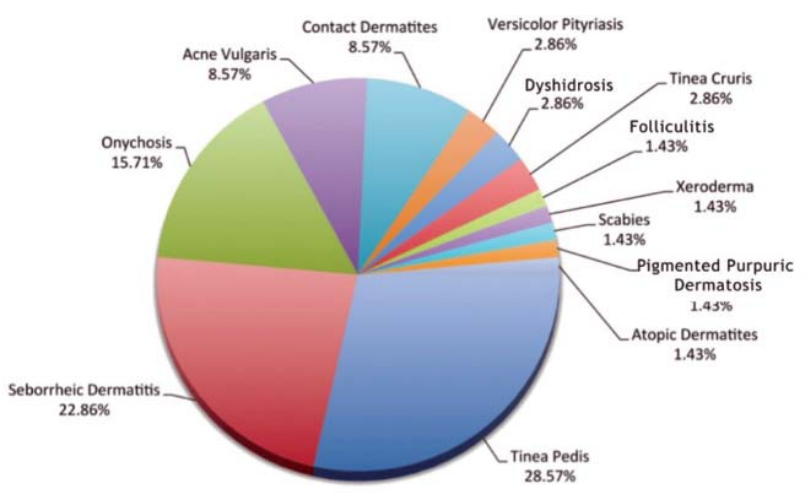

GRAPH 8: Dermatoses found in 70/271 individuals of both genders on the control group

\section{Statistical analysis}

Statistical analysis of data on dermatosis found in both the alcoholic and control groups showed that:

The association of dermatosis with alcoholism was highly significant, $(\mathrm{p}<0.005)$ as well as Relative Risk $R R=1,59$ (ic $95 \%: 1,34$ to 1,83 ) with $p=0,0002$. These data indicate that the alcoholic patient has $59 \%$ more chance of developing dermatosis (ic 95\%; 34 to $83 \%$ ) than a non-alcoholic individual.

Pellagra $(p<0,005)$, nummular eczema $(p=$ $0,008)$, chronic pigmented purpura $(p=0.032)$ and psoriasis $(p=0,003)$ were more prevalent in the alcoholic patients group, compared to the control group.

There were no significant differences between the two groups for: seborrheic dermatitis, rosacea, tinea pedis, acne vulgaris, contact dermatitis, dyshidrosis, pityriasis versicolor, tinea cruris, folliculitis, xeroderma, scabies and atopic dermatitis. 
Statistical analysis on the association of the dermatosis with gender, age and skin complexion in both groups showed no significant connection for males.

For females, there was a significant association only when white skin color was compared to other types of complexion ( $p=0,05$ for the alcoholic group and $p=0,03$ for the control group).

The statistical analysis of the association of dermatosis with gender and age in both groups showed that the prevalence of dermatosis in alcoholic patients was significantly higher before the age of 40 on both genders $(p=0,002$ for males and $p=0,036$ for females).

In the male control group the prevalence of dermatosis was also significantly higher before the age of $40(p<0,0005)$. There were no comparisons in the female control group, since $100 \%$ of the individuals with dermatosis were under the age of 40 and the group consisted of only two people.

The relative risk of developing a dermatosis was assessed only in the female alcoholic patients group, with $R R=2,75$. Even though we found a significant association in the control group, given the small number of women, the result of the statistical analysis was not considered. This analysis showed that a white-skinned female alcoholic has a $175 \%$ higher chance of developing dermatosis.

\section{DISCUSSION}

The correlation between alcoholism and dermatosis has been evaluated in the past years by several authors, without reaching a consensus and sometimes presenting controversial conclusions. Dermatology manuals mention some cutaneous diseases (rosacea, seborrheic dermatitis, porphyria cutanea tarda and pellagra) considering alcohol as one of the aggravating and/or aetiological factors ${ }^{10}$. However, there are few objective surveys that show a direct relationship between alcohol and a specific dermatosis. Thus, the present survey of cutaneous lesions found in a population of confirmed alcoholic patients that have been hospitalized for detox, seemed relevant to determine the prevalence of dermatosis in this population and to evaluate their relationship with alcoholism.

The choice of a control group consisting of Military Police officers in active duty allowed us to compare the several dermatological conditions found in both groups, because the individuals in the control are not chronic or heavy alcohol users.

Regarding the physical characteristics of the group of patients surveyed as well as those of the control group, we observed a similarity between both groups, with a predominance of male individuals. In both groups white is the prevailing skin color, a fact that can be explained by the ethnic composition of the population surveyed, since Marilia, SP has a larger white population, when compared to the number of brown, black and Asian ${ }^{2}$ individuals who reside there.

Among the alcoholic patients there were no Asian individuals.

The result of this survey, regarding the racial factor, coincided with those of Borini and Silva and Rosset and Oki, but diverged from the conclusions of Parish and Fine, in the US, where the majority of alcoholic patients was black. ${ }^{2,16,17}$

The age of the individuals in both groups surveyed varied between the ages of 20 and 60 , a fact that coincides with other surveys. ${ }^{16,17}$

The most frequent profession among the alcoholic patients surveyed was construction worker. Borini and Silva reached the same conclusion. ${ }^{2}$

In the control group, the dermatoses found were similar. However only pellagra, nummular eczema, psoriasis and pigmented purpuric dermatosis were considered prevalent among alcoholic patients in comparison to the control group.

We observed that tinea pedis, seborrheic dermatitis, pellagra, nummular eczema, acne vulgaris, psoriasis, chronic pigmented purpura, onychomycosis, contact dermatitis, sabies, xeroderma, rosacea, pityriasis versicolor, dyshidrosis, tinea cruris, atopic dermatitis were prevalent in the alcoholic patients. In the control group, we found similar dermatosis, but only pellagra, nummular eczema; psoriasis and chronic pigmented purpura were considered prevalent on alcoholic patients, in comparison with the control group, after the statistical survey. This data is consistent with the surveys published by Kostovic, Rao et al., Rosset and Oki, Higgins et al., Higgins and Du Vivier, Margolis and Roberts, although the authors did not compare the results with a control group. ${ }^{6,16,18,19,20}$

It should be noted that some dermatological occurrences (spider angiomas or spider telangiectasia, erythema, palmar erythema and leukonychia), mentioned in the literature as being connected to alcoholism, are caused by alcoholic liver disease, although they can also occur in other hepatopathies of different origins. For this reason, they were taken into consideration in this survey. ${ }^{3,18,21,22}$

In the group of alcoholic patients, pellagra was found in 15 cases, all of them males, most of them white-skinned, farm workers, with long periods of sun exposure. Pellagra was not found in the control group. All of them were malnourished and had skin lesions that varied from erythematous-violaceous, edema, sometimes with blisters and/or hemorrhagic suffusions, hyperpigmentation with mild desquamation and atrophy (always located in exposed areas). 
Most of the patients had oral lesions such as stomatitis and/or painful edema (or swelling) of the oral mucosa. Systemic manifestations in these patients were mild, because there were no simultaneous gastrointestinal or neurological disorders.

All cases experienced a progressive and big improvement of the dermatosis, during the period of hospitalization, a change credited to the access to adequate food, vitamin supplements, alcohol abstinence and non-exposure to the sun.

The results were consistent with those mentioned by Piqué-Duran et al. and Palokinan et al., who mentioned a high incidence of pellagra among the alcoholic patients surveyed. ${ }^{11,15}$ However, the results are discordant from the result obtained by Rosset and Oki, that only found one case of pellagra among 355 alcoholic patients, a fact that was probably due to the good nutritional condition of those patients. ${ }^{16}$ Data collected by Parish and Fine ${ }^{17}$, also differed, since they did not find a single case of pellagra during their survey. Thus it can be seen that the frequency of pellagra in alcoholic patients is still a point of discussion, both in Brazil and in other countries. . $^{1213,17,21}$

Nummular eczema was found in ten patients, all of them male, mostly white. There were no individuals with this condition in the control group. In all cases found in the survey, the disease affected the lower part of the legs, forming well-defined lesions.

All the patients reported previous outbreaks correlated to micro injuries and infection of the lesions. Such results were concordant with reports by Higgins and Du Vivier, Kazakevich et al., Margolis and Roberts, Sanchez and Karvonen et al, who identified a strong correlation of this pathology with alcoholism, especially in men. ${ }^{7,8,20,22,23}$ Psoriasis was found in the alcoholic group in six cases, all males, equally distributed among white, brown and black skin color. All patients reported a worsening of their lesions during periods of greater alcohol consumption and inadequate response to topical treatments. During the hospitalization period, the dermatosis got better, probably due to the alcohol abstinence. These results were similar to those of Rosset and Oki, Higgins and Du Vivier, Margolis and Roberts, Sanchez, Higgins et al., Poikolainen et al., Wolf et al, who also note the worsening of the psoriatic lesions during periods of greater alcohol consumption and unsatisfactory responses to topical treatments. . $1,19,20,22,24,25,26$ In this survey, psoriasis was not observed in females. Poikolainen et al. studied the risk factors for psoriasis in women between the ages of 18 and 50 and showed the negative interference of alcohol consumption on the efficacy of the treatment. ${ }^{27}$ The clinical form of psoriasis observed in this survey agrees with the descriptions of Higgins and $\mathrm{Du}$ Vivier $^{7}$, who also note the predominance of erythema over the scaling.

Chronic pigmented purpura was seen in six cases of patients in the alcoholic group, and in one case on the control group, most of them were white males. These patients did not have vascular, hepatic or cardiac abnormalities and the period of alcohol consumption among these individuals was the longest observed in the survey. The individual of the control group who had purpura had discrete signs of stasis. In both groups, the lesions were papular, bright red or brown confluent residual purpuric spots, forming plaques with irregular borders, located on the lower part of the legs. The results agree with those of González-Reimers et al., and Rodriguez Rodriguez et al, who believe that chronic pigmented purpura is the earliest cutaneous indicator of alcoholism..$^{28,29}$

In this survey, after the statistical analysis, there were not any significant differences between the two groups regarding the occurrence of tinea pedis, seborrheic dermatitis, acne vulgaris, contact dermatitis, scabies, xeroderma, rosacea, pityriasis versicolor, dyshidrosis, tinea cruris and atopic dermatitis.

Tinea pedis was found in 30 alcoholic patients, mostly white men and in 20 individuals from the control group. The results were in agreement with those of Parish and Fine, who found 32 cases of tinea pedis among 101 alcoholic individuals, and with Higgins and Du Vivier, who credited the frequent occurrence of the condition to the known immunosuppressive effect caused by alcohol consumption., ${ }^{7,17}$ Rosset and Oki also found 13 cases of dermatomycosis in men from the group of 355 alcoholic individuals. ${ }^{16}$ Tinea pedis was more common among alcoholic individuals, however this incidence was not statistically significant since it was also present in a high number of individuals from the control group. This may be secondary to the fact that all officers wear boots, thereby facilitating the onset of mycosis.

Seborrheic dermatitis was detected in many individuals from both groups: 18 cases in the alcoholic patients group and 16 in the control group, mostly in males. Among the alcoholic patients, 10 reported that the condition worsened during periods of higher alcohol consumption. During the hospitalization there was a clinical improvement in most patients, probably due to an improvement in personal hygiene habits normally compromised in alcoholic patients, and alcoholic abstinence. This data agrees with Kostovick, Rao et al., Sampaio et al., Rosset and Oki, Parish and Fine, and Margolis and Roberts, who claim that seborrheic dermatitis may be aggravated by alcohol consumption. ${ }^{4,6,10,16,17,20}$ Although the number of seborrheic dermatitis cases was high in the group of alcoholic patients, the statistical analysis did not show a level of significance. 
Acne vulgaris was found in 8 alcoholic patients, mostly white males, whose age varied between 20 and 35 , forming the youngest group of individuals in the study. The majority of them had the condition since their adolescence and four of them reported that the dermatosis worsened after the increase in alcohol consumption and lack of therapeutic response. This dermatosis was also observed in six individuals from the control group. The results are compatible with the data reported by Higgins, Kazakevich, and Rosset and Oki. ${ }^{78,16}$

Contact dermatitis occurred in four patients in the alcoholic group, mostly white men, always connected to their professional activity (construction workers). Six cases were observed in the control group, related to the activity they performed in the barracks (cooking). It is believed that the record of this dermatitis may have been casual, although Parish and Fine mention the presence of contact dermatitis in their survey. ${ }^{17}$

Rosacea was found only in two female, white individuals, whose age varied between 36 and 45, only in the group of alcoholic patients. Both patients reported a severe worsening of the condition due to an increase in alcohol consumption and an improvement during abstinence periods, observed during the hospitalization period. This data is in agreement with Parish and Fine17, who described cases of rosacea in two patients amongst a group of 101 alcoholic patients. They are also consistent with Rosset and $\mathrm{Oki}^{16}$, which reported 20 cases of rosacea amongst alcoholics, seven of which reported that the condition worsened with the increase of alcohol consumption.

Pityriasis versicolor was found in two patients from the group of alcoholic patients, both white, males and also in two cases from the control group. Parish and Fine and Higgins and Du Vivier describe the occurrence of superficial infections among the alcoholic patients, connecting them to the characteristic immunodeficiency found in the group. ${ }^{17,18}$

Sacbies, xeroderma, dyshidrosis, tinea cruris, folliculitis and atopic dermatitis occurred in a small number of individuals, in both groups, similar to the findings of Rosset and Oki, Parish and Fine. ${ }^{16,17}$ Onychosis (or onychogryphosis) was found in 11 individuals from the control group and in 4 from the alcoholic patients group. This result could be connected to the characteristics and habits of the individuals on the control group who played soccer frequently.
Most of the alcoholic patients surveyed had poor oral hygiene habits. Rao et al. mention the occurrence of oral abnormalities in alcoholic patients, and they believe those are connected to excessive alcohol consumption, smoking and poor hygiene. ${ }^{6}$

On the literature reviewed after more recent surveys that link alcoholism and skin disease, there is a big concern with early detection of chronic and excessive alcohol consumption, and also of markers or dermatological signs. The objective of this concern is the premise that, the sooner any pathology is diagnosed, and in this case we are talking about alcoholism, the better the treatment conditions and prognosis will be. ${ }^{18,19,29,30}$

\section{CONCLUSIONS}

The association of dermatosis and alcoholism was highly significant, as the statistical data showed.

Alcoholism can be considered a risk factor for the following dermatosis: pellagra, nummular eczema, chronic pigmented purpura and psoriasis, all of which may be considered indicators of this addiction.

Pellagra was found in a significantly higher number of individuals from the alcoholic patients group, as it is already described on the literature.

There was no difference between age and gender in the prevalence of dermatosis in alcoholics, although dermatologic diseases are more frequent before 40 .

The presence of rosacea, considered by many authors as an alcoholism marker, was not significant, probably because it is a dermatosis that occurs more frequently in women and most of the alcoholic individuals surveyed were male.

There was no significant occurrence of the following dermatosis in alcoholic patients: acne vulgaris, contact dermatitis, dyshidrosis, pityriasis versicolor, and tinea cruris. Onychosis (or onychogryphosis) was found mainly in the control group, a fact that may be linked to repeated trauma, since the individuals in this group played soccer frequently.

The prevalence of seborrheic dermatitis was not significant in the groups surveyed, although some authors state that alcoholism may exacerbate the condition. 


\section{REFERENCES}

1. Kaplan HI, Sadock BJ. Manual de psiquiatria clínica. Rio de Janeiro: MEDSI; 1992.

2. Borini P, Silva CO. Demographic, epidemiological and social aspects of alcoholism: an analysis of inpatients in psychiatric hospital. Rev ABP-APAL. 1989;11:89-96.

3. Smith KE, Fenske NA. Cutaneous manifestations of alcohol abuse. J Am Acad Dermatol. 2000;43:1-16.

4. Kostovic K, Lipozencic J. Skin diseases in alcoholics. Acta Dermatovenerol Croat. 2004;12:181-90.

5. Liu SW, Lien MH, Fenske NA. The effects of alcohol and drug abuse on the skin. Clin Dermatol. 2010; 28:391-9.

6. Rao GS. Cutaneous changes in chronic alcoholics. Indian J Dermatol Venerol Leprol. 2004;70:79-81

7. Higgins EM, Du Vivier AWP. Cutaneous disease and alcohol misuse. Br Med Bull. 1994;50:84-98.

8. Kazakevich N, Moody MN, Landau JM, Goldberg LH. Alcohol skin disorders: with a focus on psoriasis. Skin Therapy Lett. 2011;16:5-6.

9. Dediol I, Buljan M, Buljan D, Bulat V, Zivkovic MV, Situm M. Association of psoriasis and alcoholism: psychodermatological issue. Psychiatr Danub. 2009;21:9-13.

10. Sampaio SAP, Castro RM, Rivitti EA. Dermatologia básica. 3. ed. Porto Alegre: Artes Médicas; 1989

11. Piqué-Duran E, Pérez-Cejudo JA, Camesele D, Palacios-Lopis S, García-Vsquez 0. Pellagra: a clinical histopathological and epidemiological study of 7 cases. Actas Dermosifiliogr. 2012;103:51-8.

12. Nogueira A, Duarte AF, Magina S, Azevedo F. Pellagra associated with esophageal carcinoma and alcoholism. Dermatol Online J. 2009;15:8.

13. Pipili, $\mathrm{C}$, Cholongitas $\mathrm{E}$, loannidou $\mathrm{D}$. The diagnostic importance of photosensitivity dermatoses in chronic alcoholism. Dermatol Online J. 2008;14:15.

14. Delgado-Sanchez L, Godkar D, Niranjan S. Pellagra: rekindling of an old flame. Am J Ther. 2008;15:173-5.

15. Palokinam TP. Pellagre et erythemes pellagroides. Cahiers d'Etudes et de Recherches Francophones. Sante. 2005;15:205-8.

16. Rosset M, Oki, G. Skin diseases in alcoholics. Q J Stud Alcohol. 1971;32:1017-24

17. Parish LC, Fine E. Alcoholism and skin disease. Int J Dermatol. 1985;24:300-1.

18. Higgins EM, Du Vivier AWP. Invited review: alcohol and the skin. Alcohol Alcohol. 1992;27:595-602.

19. Higgins EM, Du Vivier AWP. Alcohol abuse and treatment resistance in skin disease. J Am Acad Dermatol. 1994:30:1048.

20. Margolis J, Roberts DM. Frequency of skin lesions in chronic drikers. Arch Dermatol. 1976:112:1326-7.
21. Shellow WVR. The skin in alcoholism. Int J Dermatol. 1983;22;506-10.

22. Sanchez MR. Alcohol, social behavior disorders, and their cutaneous manifestations. Clin Dermatol. 1999;17:479-89.

23. Karvonen J, Poikolainen K, Reunala T, Juvakoski T. Alcohol and smoking: risk factors for infectious eczematoid dermatitis? Acta Derm Venereol. 1992;72:208-10.

24. Higgins EM, Peters TJ, Du Vivier AWP. Smoking, drinking and psoriasis. $\mathrm{Br} J$ Dermatol. 1993;129:749-50.

25. Poikolainen K, Reunala T, Karvonen J, Lauharanta J, Kärkkainen P. Alcohol intake: a risk factor for psoriasis in young and middle aged men? Br Med J. 1990;300:780-3.

26. Wolf R, Wolf D, Ruocco V. Alcohol intake and psoriasis. Clin Dermatol. 1999;17:423 30

27. Poikolainen K, Reunala T, Karvonen J. Smoking, alcohol and life events related to psoriasis among women. Br J Dermatol. 1994;130:473-7.

28. 28. González-Reimers CE, Santolaria-Fernández F, Batista-López N, MachadoMachado P. Stasis pigmentation and chronic alcoholism. Drug Alcohol Depend. 1990;25:49.

29. Rodriguez Rodriguez E, Gonzalez Reimers E, Santolaria Fernandez FJ, Batista Lopez J, Gomez Sirvent J, Rodriguez Moreno F. et al. Eritema pipgmentario: um marcador del alcoholismo. An Med Interna. 1991;8:281-3.

30. Zaitz C, Proença NG, Ferreira AM, Arns VL. Estatísticas do Ambulatório de Dermatologia da Santa Casa de São Paulo (1977). An Bras Dermatol. 1979;54:31124

MAILING ADDRESS:

Maria Cecilia Teixeira de Carvalho Bruno

AV. Jacarandás, 3585 - Apto., 903

78550248 Sinop - MT

Brazil

E-mail:mceciliabruno@uol.com.br

How to cite this article: Bruno MCTC, Vilela MAC, Oliveira CABM. Study on dermatoses and their prevalence in groups of confirmed alcoholic individuals in comparison to a non-alcoholic group of individuals. An Bras Dermatol. 2013;88(3):368-75. 